CLINICAL STUDY

\title{
Association between glycosylated hemoglobin, left ventricular mass and aortic function in nondiabetic individuals with insulin resistance
}

\author{
Dimitrios A Stakos, Dara P Schuster ${ }^{1}$, Elizabeth A Sparks², Sophia Boudoulas Meis ${ }^{1}$, Charles F Wooley ${ }^{2}$, \\ Kwame Osei ${ }^{1}$ and Harisios Boudoulas ${ }^{3}$ \\ Division of Cardiology, Democritus University of Thrace, University Hospital of Alexandroupolis, Alexandroupolis 68100, Greece, Divisions of ${ }^{1}$ Cardiology \\ and ${ }^{2}$ Endocrinology, The Ohio State University, Columbus, Ohio, USA and ${ }^{3}$ Center for Clinical Research, Foundation of Biomedical Research, Academy of \\ Athens, Athens, Greece \\ (Correspondence should be addressed to D A Stakos; Email: dstakos@med.duth.gr)
}

\begin{abstract}
Objective: An association between glycosylated hemoglobin $(\mathrm{GHb})$ and cardiovascular mortality in nondiabetic individuals has recently been reported. Prompt detection of nondiabetic individuals with high-normal $\mathrm{GHb}$ and early cardiovascular involvement may be of value for preventive strategies. In this investigation, a possible relationship between $\mathrm{GHb}$, aortic function and left ventricular (LV) mass in nondiabetic individuals has been studied.

Methods: A total of 263 nondiabetic African-Americans, aged 22-63 (mean 42 \pm 8) years were studied. All individuals were first degree relatives of diabetic patients, had normal oral glucose tolerance test (2-h OGTT) and decreased peripheral action of insulin. LV diameters and mass (echocardiography); ascending and abdominal aortic distensibility (echocardiography, arterial pressure); pulse wave velocity (PWV; electrocardiography, Doppler); fasting glucose; $\mathrm{GHb}$; insulin sensitivity index $\left(\mathrm{S}_{\mathrm{I}}\right)$ and 2-h OGTT were measured. Multiple linear and logistic regression analyses were used to identify significant independent associations of fasting glucose; GHb; $\mathrm{S}_{\mathrm{I}}$ and 2-h OGTT with aortic function and LV mass.

Results: In fully adjusted multivariate logistic regression analysis, $\mathrm{GHb}$ predicted lower values of aortic distensibility (odds ratio (OR) 1.67 95\% CI (1.04-2.75), $P=0.04$ ); higher PWV (OR 1.79 95\% CI (1.09-2.93), $P=0.022$ ); and higher values of LV mass (OR $1.5695 \%$ CI (1.08-2.88), $P=0.029$ ). Fasting glucose, $\mathrm{S}_{\mathrm{I}}$, and $2 \mathrm{~h}$ OGTT were not associated with aortic function and LV mass.

Conclusion: Higher GHb concentrations, even within 'normal' range, are independently associated with stiffer aorta and increased LV mass and thus may detect nondiabetic individuals at increased cardiovascular risk.
\end{abstract}

European Journal of Endocrinology 157 63-68

\section{Introduction}

Patients with type 2 diabetes mellitus are at increased risk for cardiovascular complications (1). Glycosylated hemoglobin $(\mathrm{GHb})$ or hemoglobin A1c (HbA1c) concentrations have been used for decades to assess the status of long-term glycemic control in diabetic patients. Recent studies from our laboratory have shown that high GHb concentrations considered within the "normal range' may detect individuals with increased propensity for developing type 2 diabetes mellitus in the near future (2). Available information has also suggested that in the general population, high $\mathrm{GHb}$ concentrations may detect individuals at higher risk for cardiovascular mortality (3). These studies prompted the hypothesis that $\mathrm{GHb}$ may be associated with cardiovascular parameters that increase the risk for cardiovascular events, such as left ventricular (LV) mass and aortic stiffness.

The present study was undertaken to assess a possible association between $\mathrm{GHb}, \mathrm{LV}$ mass, and aortic function in nondiabetic individuals with insulin resistance.

\section{Subjects and methods}

\section{Study population}

In the diabetic clinic of The Ohio State University, we follow 3000 African-Americans with type 2 diabetes mellitus (DM), residing in Franklin County, Central Ohio. All individuals recruited for the study ( 180 females and 83 males; mean age $42 \pm 8$ years, range $22-63$ years) were first-degree relatives of these patients, with at least one 
parent with type $2 \mathrm{DM}$, as defined by the National Diabetes Data Group criteria (4). Fasting plasma glucose was < $100 \mathrm{mg} / \mathrm{dl}$, plasma glucose $2 \mathrm{~h}$ after administration of $75 \mathrm{~g}$ oral glucose load was $<140 \mathrm{mg} / \mathrm{dl}$ and insulin sensitivity index $\left(\mathrm{S}_{\mathrm{I}}\right)$ was decreased in all subjects included in the study (see Metabolic studies). Arterial blood pressure was $<140 / 90 \mathrm{mmHg}$ and body mass index $<$ 30 in all individuals.

Subjects with a history of excessive alcohol use, liver, lung, kidney or cardiovascular diseases, malignancies, hematological disorders, pregnant or breastfeeding women, and subjects with acute illness or chronic disease that required treatment with any kind of drugs were excluded prior to entry into the study. Finally, individuals who participated in endurance exercise or indulged in regular competitive sports and in a weight reduction program within the past 6 months were also excluded.

Informed written consent, approved by the institutional review board for human biomedical research at The Ohio State University, was obtained from each subject.

\section{Cardiovascular studies}

Subjects reported to the Overstreet Cardiovascular Teaching and Research Laboratory, Division of Cardiology, The Ohio State University. Medical history and physical examination including body weight and height measurement was ascertained in all individuals. Body weight and height were measured with subjects wearing an examination gown without shoes and body surface area (BSA) was calculated. Brachial artery pressure (BP) was measured by sphygmomanometry with subjects in the supine position after they had been seated for at least $5 \mathrm{~min}$. The average of two measurements was used.

All subjects underwent echocardiography using a Hewlett-Packard Model 77020A device using standard techniques.

$\boldsymbol{L V}$ mass LV diameters were measured according to the recommendations of the American Society of Echocardiography at end-diastole and end-systole, using freezeframes from the two-dimensional directed M-mode echocardiographic tracings from parasternal long axis views. LV mass and function were measured as described previously (5-7). LV mass index was derived by dividing LV mass by BSA.

Aortic distensibility Aortic distensibility is an index used to estimate the elastic properties of the aorta. As the aorta becomes stiffer, the aortic distensibility decreases, thus as the aorta becomes more elastic the aortic distensibility increases (8). Systolic and diastolic diameters of the ascending aorta were measured $3 \mathrm{~cm}$ above the aortic valve, in the two-dimensional guided M-mode echocardiographic tracings from the parasternal long axis view, as described from our laboratory (9). The average value of 5 beats was used for analysis. Systolic abdominal aortic diameter was measured at the maximal anterior motion of the aorta, and diastolic abdominal aortic diameter was measured $100 \mathrm{~ms}$ before the beginning of the anterior motion of the aorta. Aortic distensibility $\left(\mathrm{cm}^{2}\right.$ dynes $^{-1} 10^{-6}$ ) was measured using the formula: $2 \times$ (systolic aortic diameter)-(diastolic aortic diameter)/ (diastolic aortic diameter) $\times$ (pulse pressure).

Pulse wave velocity (PWV) For the measurements of aortic PWV the Doppler flow velocities from the carotid artery and femoral arteries were recorded simultaneously with the electrocardiogram. The time from the beginning of the QRS complex on the electrocardiogram to the upstroke of the carotid artery Doppler flow velocity and the time from the beginning of the QRS complex to the upstroke of the left femoral artery Doppler flow velocity were measured. PWV was calculated as the ratio of the distance between the carotid artery and the femoral artery (m) over the time (s) required for the pulse wave to travel from the carotid artery to the femoral artery $(8,9)$.

\section{Metabolic studies}

After a 10-12 h overnight fast, all participants referred to the General Clinical Research Center (GCRC) of The Ohio State University Medical Center. Blood was drawn for metabolic, biochemical, and hematological parameters. With subjects in the supine position, two i.v. needles were inserted to forearm veins and kept clear with $0.9 \%$ normal saline infusion. One of the i.v. lines was used to draw samples of blood and the other for glucose and insulin administration.

Oral glucose tolerance test (OGTT) Each subject was instructed to ingest $250 \mathrm{~g}$ carbohydrate in their regular meals for 3 days before the study. Following a 10-12 h overnight fast, all subjects ingested a $75 \mathrm{~g}$ oral glucose load (Koladex, Baltimore, MD, USA) in a total volume of $250 \mathrm{ml}$ over a 2-min period. Blood samples for serum glucose, insulin, and c-peptide were obtained at baseline, and at 30, 60, 90, and $120 \mathrm{~min}$ after glucose administration. Glucose tolerance status was defined using the National Diabetes Data Group criteria (4).

Insulin sensitivity index All blood samples were centrifuged at $4{ }^{\circ} \mathrm{C}$ and the sera were frozen and stored at $-20{ }^{\circ} \mathrm{C}$ until assay. $\mathrm{S}_{\mathrm{I}}$ was measured using the frequently sampled i.v. glucose tolerance test. The minimal model software program (MINIMOD; copyright $\mathrm{RN}$ Bergman, 1986) was used as previously described (10). 
Analytical methods Serum glucose concentrations were measured by the hexokinase method using a glucose autoanalyzer (Yellow Spring Instruments, Yellow Spring, OH, USA). The serum insulin and c-peptide levels were determined by a standard doubleantibody RIA technique at the core laboratories of The Ohio State University Hospitals. The HbA1 was measured by the cationic, microcolumn chromatographic technique (Isolab, Akron, OH, USA). The normal reference range was $4.1-8.0 \%$. Our previous $\mathrm{HbAl}$ assay measured $\mathrm{HbAla}, \mathrm{HbAlb}$, and GHb. GHb is the major component of $\mathrm{HbA} 1$, accounting for at least $80 \%$ of the total $\mathrm{HbAl}$ in our assay. Thus, to be consistent with the $\mathrm{GHb}$ data that have been used in both the Diabetes Control and Complications Trial and the UK Prospective Diabetes Study, we have converted the $\mathrm{HbA} 1$ to GHb equivalent. The normal GHb range in our study population was $2.2-6.4 \%$. Total serum cholesterol, high-density lipoprotein cholesterol (HDLC), and triglycerides were measured using standard enzymatic methods. Low density lipoprotein (LDL) cholesterol was calculated using Friedwald's equation, where LDL cholesterol $=($ total cholesterol - HDL cholesterol-triglyceride) $/ 5$, for serum triglycerides < $400 \mathrm{mg} / \mathrm{dl}$.

\section{Statistical analysis}

Subjects' characteristics are presented as mean \pm 1 s.D., unless otherwise indicated. GHb was normally distributed in the study population. The mean value of ascending and abdominal aortic distensibility of each individual was used as overall aortic distensibilty. Univariate linear regression analysis was performed to define significant determinants of aortic distensibility, PWV and LV mass. Variables included in the model were total cholesterol, LDL cholesterol, HDL cholesterol, triglycerides, age, gender, systolic BP, diastolic BP, BSA, smoking status. Variables having a significant association with aortic distensibility, PWV or LV mass entered into multiple linear regression model together with each one of the glycemic factors $\mathrm{GHb}$, fasting glucose, 2-h OGTT and $\mathrm{S}_{\mathrm{I}}$, to identify significant independent associations between aortic distensibility, PWV or LV mass and these factors. In order to show a possible predictive value of $\mathrm{GHb}$, fasting glucose, 2-h OGTT and $S_{I}$ for lower aortic distensibility and higher PWV and LV mass, univariate and multivariate logistic regression analysis were performed. For this reason, aortic distensibility, PWV and LV mass were divided into lower and higher levels according to their median values. Statistical analysis was performed using SPSS v 11.0 (SPSS Inc., Chicago, IL, USA). A $P$ value of $<0.05$ was considerate statistically significant.

\section{Results}

Table 1 shows the baseline characteristics of the study population.

Univariate linear regression analysis demonstrated that from the demographic parameters, age, systolic BP and HDL cholesterol were significantly associated with overall aortic distensibility (Table 2). These factors entered in multiple linear regression analysis together with the glycemic factors $\mathrm{GHb}$, fasting glucose, 2-h OGTT and $\mathrm{S}_{\mathrm{I}}$. GHb was the only factor independently and significantly associated with aortic distensibility $(b=-0.177, t=-2.121, P=0.03$, Table 3$)$.

Univariate linear regression analysis demonstrated that from the demographic parameters only age was significantly associated with PWV (Table 2). In multiple linear regression analysis $\mathrm{GHb}(b=0.153, t=1.893$, $P=0.04)$ and fasting glucose $(b=0.209, t=2.581$, $P=0.01)$ were independently associated with PWV (Table 3).

$\mathrm{GHb}$ was also independently associated with LV mass index after a multiple linear regression analysis adjusted for age, systolic BP, gender and BSA $(b=0.173, t=2.376$, $P=0.02$, Table 3 ).

In univariate models of logistic regression analysis only $\mathrm{GHb}$ was significantly associated with lower aortic distensibility (OR 1.89 95\% CI (1.19-3.03), $P=0.008$ ); higher PWV (OR 1.92 95\% CI (1.21-3.06), $P=0.005$ ) and higher LV mass index (OR $1.74 \quad 95 \%$ CI (1.08-2.88), $P=0.02$, Table 4 ), whereas fasting glucose, 2-h OGTT and $S_{\text {I }}$ did not.

In multivariate models of logistic regression analysis, $\mathrm{GHb}$ was the only glycemic factor that predicts lower

Table 1 Baseline characteristics of the study population $(n=263)$.

\section{Characteristics}

Age (years)

Gender (M/F)

Weight $(\mathrm{kg})$

Smoking (\%)

Body surface area (BSA, $\mathrm{m}^{2}$ )

Body mass index (BMI)

$\mathrm{GHb}(\%)$

Fasting serum glucose $(\mathrm{mg} / \mathrm{dl})$

Glucose $120 \mathrm{~min}$ during OGTT $(\mathrm{mg} / \mathrm{dl})$

Fasting serum insulin $(\mu \mathrm{U} / \mathrm{ml})$

Insulin $\mathrm{S}_{\mathrm{I}}\left(\mathrm{min}^{-1} \times \mathrm{uU}^{-1} \times \mathrm{ml}^{-1}\right)$

Systolic blood pressure $(\mathrm{mmHg})$

Diastolic blood pressure $(\mathrm{mmHg})$

Pulse pressure $(\mathrm{mmHg})$

Pulse wave velocity $(\mathrm{m} / \mathrm{s})$

Ascending aortic distensibility $\left(\mathrm{cm}^{2} \cdot \mathrm{dyn}^{-1} \cdot 10^{-6}\right)$

Abdominal aortic distensibility $\left(\mathrm{cm}^{2} \cdot \mathrm{dyn}^{-1} \cdot 10^{-6}\right)$

Overall, aortic distensibility $\left(\mathrm{cm}^{2} \cdot \mathrm{dyn}^{-1} \cdot 10^{-6}\right)$

Left ventricular mass index $\left(\mathrm{g} / \mathrm{m}^{2}\right)$

Total cholesterol (mg/dl)

High density lipoprotein cholesterol (HDL, mg/dl)

Triglycerides $(\mathrm{mg} / \mathrm{dl})$

Low density lipoprotein cholesterol (LDL, mg/dl)

$42.0 \pm 8.0$
$83 / 180$
$91.70 \pm 23.8$
11
$1.99 \pm 0.23$
$23.02 \pm 3.47$
$4.94 \pm 0.85$
$80.90 \pm 16.3$
$99.46 \pm 26.2$
$12.56 \pm 6.7$
$2.50 \pm 1.6$
$124.5 \pm 15.5$
$81.00 \pm 10.5$
$43.0 \pm 11.5$
$9.6 \pm 2.1$
$3.18 \pm 1.69$
$4.04 \pm 1.70$
$3.38 \pm 1.39$
$62.00 \pm 14.13$
$182.30 \pm 34.71$
$49.42 \pm 13.65$
$101.23 \pm 67.24$
$112.44 \pm 34.08$

Values are expressed as mean \pm 1 S.D., OGTT indicates oral glucose tolerance test. 
Table 2 Univariate model of linear regression analysis. Correlations between cardiovascular risk factors and aortic distensibility, pulse wave velocity (PWV), and left ventricular (LV) mass.

\begin{tabular}{lcll}
\hline & $\begin{array}{c}\text { Aortic dis- } \\
\text { tensibility } \\
\left(R^{2} / P\right)\end{array}$ & PWV $\left(R^{2} / P\right)$ & $\begin{array}{c}\text { LV mass } \\
\left(R^{2} / P\right)\end{array}$ \\
\hline Age & $0.092 / 0.001^{*}$ & $0.040 / 0.001^{*}$ & $0.061 / 0.001^{*}$ \\
Gender & $0.00 / 0.955$ & $0.005 / 0.352$ & $0.063 / 0.0014^{*}$ \\
$\begin{array}{l}\text { Systolic blood } \\
\text { pressure }\end{array}$ & $0.176 /<0.001^{*}$ & $0.011 / 0.270$ & $0.213 / 0.0001^{*}$ \\
$\begin{array}{l}\text { Diastolic blood } \\
\text { pressure }\end{array}$ & $0.015 / 0.135$ & $0.002 / 0.691$ & $0.018 / 0.411$ \\
$\begin{array}{l}\text { Total cholesterol } \\
\text { LDL cholesterol }\end{array}$ & $0.00 / 0.913$ & $0.0019 / 0.588$ & $0.009 / 0.006$ \\
HDL cholesterol & $0.054 / 0.916$ & $0.012 / 0.180$ & $0.011 / 0.190$ \\
Triglycerides & $0.009 / 0.265$ & $0.014 / 0.154$ & $0.005 / 0.394$ \\
Body surface area & $0.00 / 0.0966$ & $0.006 / 0.322$ & $0.004 / 0.216$ \\
\hline
\end{tabular}

LDL, low density lipoprotein cholesterol; HDL, high density lipoprotein cholesterol.

*Indicates $P<0.05$.

aortic distensibility (OR 1.67 95\% CI (1.04-2.75), $P=0.04$ ); higher PWV (OR 1.79 95\% CI (1.09-2.93), $P=0.022)$ and higher LV mass index (OR $1.6795 \% \mathrm{CI}$ (1.02-2.58), $P=0.044)$, independent of age, gender, systolic BP, diastolic BP, BSA, smoking status, total cholesterol, LDL cholesterol, HDL-C, and triglycerides. After adjustment for all these factors, GHb levels were inversely correlated with overall aortic distensibility (Fig. 1).

\section{Discussion}

The present study demonstrates that $\mathrm{GHb}$, even in concentrations considered within the 'normal range', is independently related to LV mass and aortic function. Higher $\mathrm{GHb}$ concentrations were associated with

Table 3 Fully adjusted associations of fasting glucose, $\mathrm{GHb}, 2-\mathrm{h}$ OGTT and $S$, with aortic distensibility, pulse wave velocity (PWV) and LV mass. Multiple linear regression analysis.

\begin{tabular}{lrrr}
\hline & \multicolumn{1}{c}{ Beta } & \multicolumn{1}{l}{$\boldsymbol{t}$} & \multicolumn{1}{l}{$\boldsymbol{P}$} \\
\hline Aortic distensibility & & & \\
Fasting glucose & 0.094 & 1.086 & 0.280 \\
GHb & -0.177 & -2.121 & 0.034 \\
2 h OGTT & -0.045 & -0.520 & 0.604 \\
S $_{\text {IWV }}$ & -0.124 & -1.379 & 0.171 \\
Fasting glucose & 0.209 & 2.581 & \\
GHb & 0.183 & 2.293 & 0.011 \\
2 h OGTT & 0.085 & 1.079 & 0.030 \\
S & -0.144 & -1.749 & 0.282 \\
LV mass & & & \\
Fasting glucose & 0.126 & 1.081 & 0.082 \\
GHb & 0.173 & 2.376 & 0.023 \\
2 h OGTT & 0.077 & 1.590 & 0.098 \\
S I & -0.108 & -1.336 & 0.117 \\
\hline
\end{tabular}

$\mathrm{GHb}$, glycosylated hemoglobin; OGTT, oral glucose tolerance test; $\mathrm{S}_{\mathrm{l}}$, insulin sensitivity index; LV, left ventricle.
Table 4 Assessment of predictive value of glycemic factors (fasting glucose, GHb, 2-h OGTT and $S_{1}$ ) for lower aortic distensibility, higher PWV and higher LV mass. Univariate model of logistic regression analysis. $\mathrm{GHb}$ was the only glycemic factor independently associated with aortic distensibility, PWV and LV mass.

\begin{tabular}{llll}
\hline & OR & $95 \%$ Cl & $P$ \\
\hline Aortic distensibility & & & \\
Fasting glucose & 1.01 & $0.98-1.04$ & 0.434 \\
GHb & 1.89 & $1.18-3.03$ & 0.008 \\
2-h OGTT & 1.01 & $0.99-1.02$ & 0.516 \\
S $_{\text {I }}$ & 0.98 & $0.94-1.01$ & 0.227 \\
PWV & 1.03 & $0.99-1.05$ & 0.065 \\
Fasting glucose & 1.92 & $1.21-3.06$ & 0.005 \\
GHb & 1.01 & $0.99-1.02$ & 0.369 \\
2-h OGTT & 1.04 & $0.99-1.08$ & 0.062 \\
S $_{\text {I }}$ & 1.02 & $0.99-1.07$ & 0.081 \\
LV mass & 1.74 & $1.08-2.88$ & 0.023 \\
Fasting glucose & 1.02 & $0.98-1.02$ & 0.871 \\
GHb & 1.03 & $0.99-1.07$ & 0.189 \\
2-h OGTT & &
\end{tabular}

$\mathrm{GHb}$, glycosylated hemoglobin; OGTT, oral glucose tolerance test; $\mathrm{S}_{\mathrm{l}}$, insulin sensitivity index; LV, left ventricle.

greater LV mass and PWV, and lower aortic distensibility in asymptomatic nondiabetic individuals with normal glucose tolerance. On the contrary, $\mathrm{S}_{\mathrm{I}}$, fasting glucose and $2 \mathrm{~h}$ OGTT were not associated with LV mass and aortic function.

Aortic distensibility and PWV are indices which have been used to estimate the elastic properties of the aorta. It is known that a decreased aortic distensibility and/or increased PWV (i.e. stiffer aorta) often are present in patients with atherosclerosis, arterial hypertension, diabetes mellitus and older age $(6,11,12)$. Epidemiologic studies have shown that aortic stiffness is a

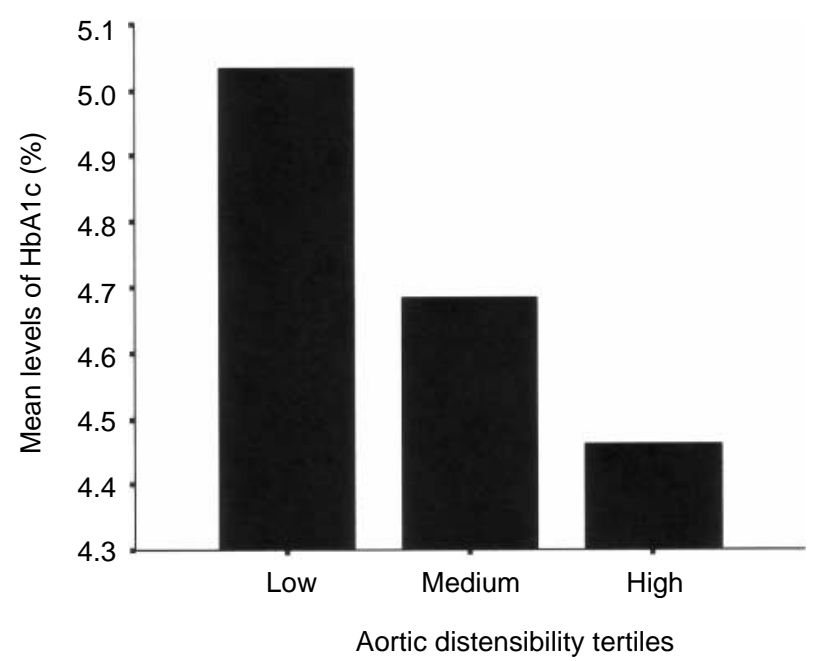

Figure $1 \mathrm{HbA} 1 \mathrm{c}$ levels (modelled continuously) were inversely correlated with overall aortic distensibility tertiles (Kendall's $\tau-b$, $t=-0.225, P=0.001)$. Model adjusted for age, gender, BSA, smoking status, lipid profile, and systolic blood pressure. 
prognostic indicator for cardiovascular morbidity and mortality in the general population, independent of other risk factors $(13,14)$. Increased aortic stiffness will result in higher systolic $\mathrm{BP}$, thus adding load to the $\mathrm{LV}$, which may increase the LV mass; increased LV mass is also a prognostic indicator for cardiovascular morbidity and mortality in the general population, independent of other risk factors $(15,16)$. In the present study, individuals with higher $\mathrm{GHb}$ levels had both increased aortic stiffness and LV mass.

$\mathrm{Hb}$, as well as other proteins, undergoes nonenzymatic glycosylation. For $\mathrm{Hb}$, glycosylation occurs when glucose is added to one or both N-terminals of the beta chains of the molecule. Because erythrocytes are freely permeable to glucose, the rate of $\mathrm{Hb}$ glycosylation is directly related to plasma glucose concentrations. In nondiabetic individuals, only a small percentage of the hemoglobin in red blood cells is glycosylated. In contrast, in diabetic patients, $\mathrm{GHb}$ concentrations are much higher compared with normals, especially in cases with poor glycemic control. Thus, in patients with diabetes mellitus, measurement of $\mathrm{GHb}$ concentrations provides an accurate picture of overall glycemic control for the previous 3 months. Likewise, concentrations of $\mathrm{GHb}$ in nondiabetic individuals indirectly indicate average plasma glucose levels.

Theoretically, GHb may reflect universal tissue protein glycation and might be a much better index for overall biological effects of glucose above and beyond of one single measure of glucose levels. It is known that nonenzymatic glycosylation of proteins and formation of advanced glycation end-products may have adverse effects on tissue structure and function by generation of reactive oxygen species $(17,18)$. Furthermore, other studies have shown that red blood cells containing increased concentrations of GHb bind nitric oxide more avidly, leading to nitric oxide inactivation, reduced nitric oxide delivery to tissues and reduced relaxant responses of microvessels to agonists such as bradykinin (19). Nonenzymatic glycosylation of the elastin and collagen of the aortic wall may contribute to the functional abnormalities of the aorta often present in patients with diabetes mellitus (20). The present study further demonstrates that high-normal $\mathrm{GHb}$ concentrations may influence aortic function even in nondiabetic individuals with normal glucose tolerance.

$\mathrm{GHb}$ concentration increases with age due to a small but steady decline in pancreatic $\beta$-cell function (21). It is also known that aortic distensibility decreases, while PWV and LV mass increase with age (6). In the present study, however, the association between $\mathrm{GHb}$, aortic distensibility and LV mass persists after adjustment for age.

In the present study, individuals with a family history of type 2 diabetes mellitus, normal OGTT and insulin resistance were included. Thus, the data from the study cannot be extrapolated to the general population. Furthermore, the studied individuals were AfricanAmericans, a population that manifest a greater prevalence and incidence of type 2 diabetes and its complications compared with their white counterparts (22). For these reasons, caution must be exercised when extrapolating the findings of this study to other populations. The study suggests however that cardiovascular involvement may precede the onset of frank diabetes, at the time when plasma glucose is within normal range and $\mathrm{GHb}$ in the high-normal levels. Since an association between $\mathrm{GHb}$, aortic stiffness and $\mathrm{LV}$ mass was found in the present study, GHb may be used in the risk assessment for early cardiovascular involvement in individuals at high risk for developing type 2 diabetes mellitus.

Ko et al. (23) have shown that in nondiabetic individuals with normal glucose tolerance, $\mathrm{GHb}$ concentrations were associated with age, blood pressure, total and LDL cholesterol, apolipoprotein B, and urate concentration. However, when age and gender were included as covariates, only total and LDL cholesterol remained associated with $\mathrm{GHb}$ levels. Further, aortic function and LV mass were not measured in this study. In addition, the study of Ko et al. (24) was performed in a Chinese population, who may differ from African-Americans in so far as cardiovascular risks are concern (25).

Other studies have also shown that $\mathrm{GHb}$ is associated with the extent of coronary atherosclerosis in nondiabetic subjects with normal glucose tolerance and coronary artery disease (26). The same was found for carotid artery atherosclerosis (27). In the present study, only individuals without evidence of atherosclerotic disease were included. To our knowledge, extensive studies to define the extent of coronary atherosclerosis in this group of asymptomatic individuals were not performed.

In conclusion, this study demonstrates for the first time that high $\mathrm{GHb}$ concentrations considered within the 'normal range' are associated with lower aortic distensibility and higher LV mass. Thus, GHb may be a useful marker of both cardiovascular involvement and increased cardiovascular risk in nondiabetic individuals, better than fasting glucose or 2-h OGTT. Studies have shown that dietary and lifestyle modification may decrease $\mathrm{GHb}$ concentrations (28). Whether lifestyle modifications and/or other pharmacological interventions have any significant effect on aortic function, LV mass or cardiovascular complications in this population remains to be defined $(29,30)$.

\section{Acknowledgements}

We wish to thank the volunteers of the study, the registered nurses and dietitians in the GCRC, the Core Laboratory, the Overstreet Teaching and Research Cardiovascular Laboratory, Columbus Ohio, and the NIH GCRC-RR0034. Dr George Xalikias, MD, PhD provided valuable statistical contribution. 


\section{Funding}

The study was partially supported by NIH NIDDK DK 48127 grant.

\section{References}

1 Kannel WB \& McGee DL. Diabetes and cardiovascular disease. The Framingham study. JAMA 1979241 2035-2038.

2 Osei K, Rhinesmith S, Gaillard T \& Schuster D. Is glycosylated hemoglobin A1c a surrogate for metabolic syndrome in nondiabetic, first-degree relatives of African-American patients with type 2 diabetes? Journal of Clinical Endocrinology and Metabolism 200388 4596-4601.

3 Khaw KT, Wareham N, Bingham S, Luben R, Welch A \& Day N. Association of hemoglobin A1c with cardiovascular disease and mortality in adults: the European prospective investigation into cancer in Norfolk. Annals of Internal Medicine 2004141 413-420.

4 The Expert Committee on the Diagnosis and Classification of Diabetes Mellitus. Follow-up report on the diagnosis of diabetes mellitus. Diabetes Care 200326 3160-3167.

5 Sahn DJ, DeMaria A, Kisslo J \& Weyman A. The committee on M-mode standardization of the American Society of Echocardiography. Recommendations regarding quantification in M-mode echocardiography: results of a survey of echocardiographic measurements. Circulation 197858 1072-1083.

6 Kallaras K, Sparks EA, Schuster DP, Osei K, Wooley CF \& Boudoulas H. Cardiovascular effects of aging. Interrelationships of aortic, left ventricular, and left atrial function. Herz 200126 129-139.

7 Boudoulas H. Determination of left ventricular mass in clinical practice. Journal of Heart Valve Disease $19976222-227$.

8 Boudoulas $\mathrm{H}$ \& Wooley CF. Aortic function. In Functional Abnormalities of the Aorta, edn 1, ch 1, pp 17-22. Eds H Boudoulas, P Toutouzas \& CF Wooley. New York: Futura Publishing, 1996.

9 Hirata K, Triposkiadis F, Sparks E, Bowen J, Wooley CF \& Boudoulas H. The Marfan syndrome: abnormal aortic elastic properties. Journal of the American College of Cardiology 199118 57-63.

10 Bergman RN, Prager R, Volund A \& Olefsky JM. Equivalence of the insulin sensitivity index in man derived by the minimal model method and euglycemic glucose clamp. Journal of Clinical Investigation $1987 \mathbf{7 9} 790-800$.

11 van Popele NM, Grobbee DE, Bots ML, Asmar R, Topouchian J, Reneman RS, Hoeks AP, van der Kuip DA, Hofman A \& Witteman JC. Association between arterial stiffness and atherosclerosis: the Rotterdam Study. Stroke 200132 454-460.

12 Stefanadis C, Wooley CF, Bush CA, Kolibash AJ \& Boudoulas H. Aortic distensibility abnormalities in coronary artery disease. American Journal of Cardiology 198759 1300-1304.

13 Oren A, Vos LE, Uiterwaal CS, Gorissen WH, Grobbee DE \& Bots ML. Aortic stiffness and carotid intima-media thickness: two independent markers of subclinical vascular damage in young adults. European Journal of Clinical Investigation 200333 949-954.

14 Laurent S, Boutouyrie P, Asmar R, Gautier I, Laloux B, Guize L, Ducimetiere P \& Benetos A. Aortic stiffness is an independent predictor of all-cause and cardiovascular mortality in hypertensive patients. Hypertension 200137 1236-1241.

15 Safar ME, Levy BI \& Struijker-Boudier H. Current perspectives on arterial stiffness and pulse pressure in hypertension and cardiovascular diseases. Circulation 2003107 2864-2869.
16 Levy D, Garrison RJ, Savage DD, Kannel WB \& Castelli WP. Prognostic implications of echocardiographically determined left ventricular mass in the Framingham Heart Study. New England Journal of Medicine 1990322 1561-1566.

17 Wautier JL \& Schmidt AM. Protein glycation: a firm link to endothelial cell dysfunction. Circulation Research 2004 95 233-238.

18 Angulo J, Sanchez-Ferrer CF, Peiro C, Marin J \& RodriguezManas L. Impairment of endothelium-dependent relaxation by increasing percentages of glycosylated human hemoglobin. Possible mechanisms involved. Hypertension $1996 \mathbf{2 8} 583-592$.

19 Brownlee M, Vlassara H, Kooney A, Ulrich P \& Cerami A. Aminoguanidine prevents diabetes-induced arterial wall protein cross-linking. Science 1986232 1629-1632.

20 Singer DE, Nathan DM, Anderson KM, Wilson PW \& Evans JC. Association of $\mathrm{HbA1c}$ with prevalent cardiovascular disease in the original cohort of the Framingham Heart Study. Diabetes $1992 \mathbf{4 1}$ 202-208.

21 Yates AP \& Laing I. Age-related increase in hemoglobin A1c and fasting plasmaglucose is accompanied by a decrease in beta cell function without change in insulin sensitivity: evidence from a cross-sectional study of hospital personnel. Diabetic Medicine 2002 $19254-258$.

22 Harris MI, Flegal KM, Cowie C, Eberhardt MS, Goldstein DE, Little RR, Wiedmeyer HM \& Byrd-Holt DD. Prevalence of diabetes, impaired fasting glucose, and impaired glucose tolerance in US adults. The Third National Health and Nutrition Survey 19881994. Diabetes Care $199821518-524$.

23 Ko GT, Chan JC, Woo J, Lau E, Yeung VT, Chow CC, Li JK, So WY, Chan WB \& Cockram CS. Glycated haemoglobin and cardiovascular risk factors in Chinese subjects with normal glucose tolerance. Diabetic Medicine 199815 573-578.

24 Osei K, Gaillard T \& Schuster D. Cardiovascular risk factors in African-Americans with varying degrees of glucose intolerance. Diabetes Care 199922 1588-1590.

25 Meis SB, Schuster D, Gaillard T \& Osei K. Metabolic syndrome in nondiabetic, obese, first-degree relatives of African American patients with type 2 diabetes: African American triglycerides-HDL$\mathrm{C}$ and insulin resistance paradox. Ethnicity and Disease 200616 830-836.

26 Sasso FC, Carbonara O, Nasti R, Campana B, Marfella R, Torella M, Nappi G, Torella R \& Cozzolino D. Glucose metabolism and coronary heart disease in patients with normal glucose tolerance. JAMA 2004291 1857-1863.

27 Vitelli LL, Shahar E, Heiss G, McGovern PG, Brancati FL, Eckfeldt JH \& Folsom AR. Glycosylated hemoglobin level and carotid intimal-medial thickening in nondiabetic individuals. The Atherosclerosis Risk in Communities Study. Diabetes Care 199720 1454-1458.

28 Sargeant LA, Khaw K-T, Bingham S, Day NE, Luben RN, Oakes S, Welch A \& Wareham NJ. Fruit and vegetable intake and population glycosylated haemoglobin levels: the EPIC-Norfolk Study. European Journal of Clinical Nutrition $200155342-348$.

29 Chiasson JL, Josse RG, Gomis R, Hanefeld M, Karasik A \& Laakso M. STOP-NIDDM Trail Research Group. Acarbose for prevention of type 2 diabetes mellitus: the STOP-NIDDM randomised trial. Lancet $20023592072-2077$.

30 Stakos D, Schuster DP, Sparks EA, Osei K, Wooley CF \& Boudoulas H. Long term cardiovascular effects of oral antidiabetic agents in non-diabetic patients with insulin resistance: double blind, prospective, randomised study. Heart 200591 589-594.

Received 26 February 2007

Accepted 10 April 2007 